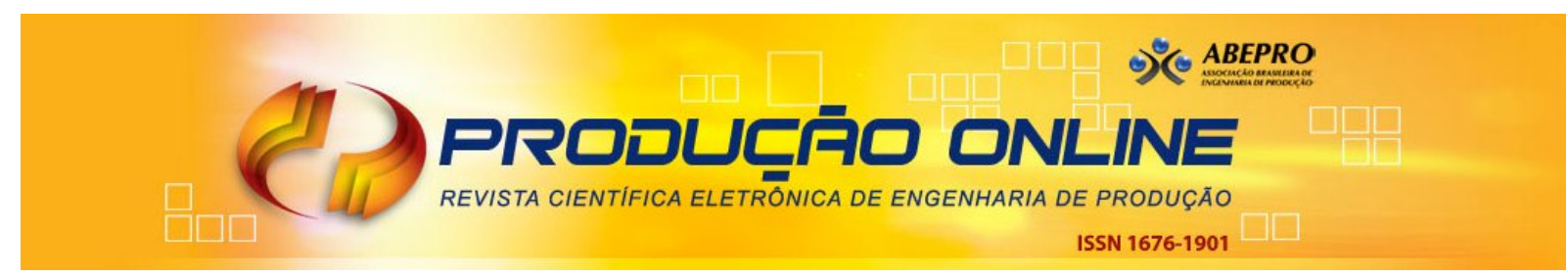

\title{
DIMENSÕES DA QUALIDADE PERCEBIDA EM RELACIONAMENTOS B2B: UM ESTUDO DE CASO NO SETOR PÚBLICO
}

\section{DIMENSIONS OF QUALITY PERCEIVED IN B2B RELATIONSHIPS: A CASE STUDY IN THE PUBLIC SECTOR ${ }^{1}$}

\author{
Gabriel Lara Rodrigues* E-mail: gabrielrodriguesbh@yahoo.com.br \\ Noel Torres Júnior* E-mail: noel@face.ufmg.br \\ *Universidade Federal de Minas Gerais (UFMG), Belo Horizonte, MG
}

\begin{abstract}
Resumo: O aumento da horizontalização da produção ampliou a discussão sobre a qualidade para além da fronteira da organização. Além disso, os vínculos entre os compradores e os fornecedores passaram a ter um foco maior, ultrapassando a visão estritamente transacional de produção ou de serviço, passando a abranger perspectivas mais dinâmicas como a de relacionamento e a de redes. Neste contexto, à luz das dimensões da Qualidade de Relacionamento entre Empresas propostas por Holmlund (1997), o trabalho busca identificar as especificidades que compõem a qualidade do relacionamento entre um órgão público e seus fornecedores privados. Por meio de um Estudo de Caso, o trabalho analisa as especificidades na qualidade do relacionamento entre um órgão público (Intendência da Cidade Administrativa de Minas Gerais) e seus fornecedores privados na área de facilities, mais especificamente em contratos de serviço de reprografia e impressão. O estudo verificou que a Qualidade de Relacionamento entre empresas envolve diferentes pessoas e funções com diferentes necessidades e importâncias. Verificou-se que a idéia de relacionamentos recíprocos, de longo prazo e mutuamente benéficos, com padrões de compartilhamento de informação e transferência de recursos é desestimulada por diversos normativos legais que limitam o relacionamento do Estado com seus prestadores de serviços, principalmente quanto ao tempo de relacionamento, ao custo e à flexibilidade.
\end{abstract}

Palavras-chave: Qualidade Percebida de Relacionamento. Gestão de Fornecedores. Acordo de Nível de Serviço. Relacionamentos de Negócios.

\begin{abstract}
The increasing production horizontalization expanded the discussion on quality beyond the border of the organization. Furthermore, the links between buyers and suppliers have now a greater focus, beyond the strictly transactional view of production or service to encompass more dynamic prospects such as relationships and networks. In this context, in the light of the dimensions of Relationship Quality between Companies proposed by Holmlund (1997), the present research aims to identify the specificities which characterize the relationship quality of a public agency and its private suppliers, more specifically in reprography and printing service contracts. The study found that the Quality of Relationship between companies involves different people and functions with different needs and importance. It has been found that the idea of reciprocal, long-term and mutually beneficial relationships, with shared information and resource transfer standards, is discouraged by many legal regulations that limit the government's relationship with its service providers, especially regarding length of relationship, cost and flexibility.
\end{abstract}

Keywords: Perceived Relationship Management. Suppliers Management. Service Level Agreement. Business Relationships.

${ }^{1}$ Trabalho advindo de dissertação de mestrado em Administração pelo CEPEAD-UFMG.

Revista Produção Online, Florianópolis, SC, v.15, n. 4, p. 1426-1456, out./dez. 2015. 


\section{INTRODUÇÃO}

A desintegração vertical vem sendo apontada como fundamental para que organizações obtenham vantagem competitiva. Esta prática permite maior foco nas atividades centrais do negócio de cada instituição, permitindo maior geração de valor (CHOPRA; MEINDL, 2011; PIRES; VIVALDINI, 2010; PORTER, 2004). Contudo, a desintegração vertical de processos leva a novas formas de relacionamento com os fornecedores. Cria-se assim uma cadeia de suprimentos, regida por vínculos contratuais em substituição aos vínculos de cooperação hegemônica da estruturação vertical (ABRAMCZUK, 2001).

Este processo de horizontalização não escapou ao setor público. Principalmente a partir da reforma gerencial, novas formas de relacionamento com entidades privadas foram introduzidas ou incentivadas (BRESSER-PEREIRA, 1998).

Neste contexto, surge uma economia cada vez mais horizontalizada, levando o debate da qualidade para além da fronteira da organização. A desintegração vertical como forma de se buscar vantagem competitiva gerou a necessidade de se discutir a qualidade não só no processo produtivo interno, mas também externamente, no relacionamento entre instituições (HOLMLUND; KOCK, 1995; HOLMLUND, 2008).

Pode-se afirmar que o gerenciamento da Cadeia de Suprimentos dos setores privados e públicos apresentam diferenças (LARSON, 2009). Tadelis (2012) afirma que os setores público e privado diferem-se dramaticamente na forma de aquisição de bens e serviços. Neste contexto, as empresas privadas não estão sujeitas a certos tipos de entraves jurídicos, se comparadas às organizações públicas. As empresas privadas dispõem de um grau de liberdade maior no estabelecimento de formas de gerenciamento com seus fornecedores, uma vez que podem: definir a forma como pretendem se relacionar com seus fornecedores; definir o tempo que perdurará esta ligação; escolher seus parceiros comerciais; negociar livremente seus preços; e assim por diante. Já o direito público, que rege a coisa pública, estabelece que a organização pública só pode agir da forma estabelecida em lei. E são vários os regimentos legais para estabelecer como as organizações públicas podem agir. São exemplos: a lei determina a forma como tais instituições públicas podem contratar, o tempo máximo dos contratos, a necessidade de uma seleção Revista Produção Online, Florianópolis, SC, v.15, n. 4, p. 1426-1456, out./dez. 2015. 
isonômica de fornecedores, a forma de composição dos preços, dentre outros (PIETRO, 2015). Por tudo isto, pode-se afirmar, que relacionamentos envolvendo organizações públicas são mais limitados que os exclusivamente privados. Neste mesmo sentido, Tadelis (2012) afirma que as regulações de contratos públicos impõem restrições que não estão presentes no setor privado, e que a ausência dessas restrições gera uma flexibilidade no setor privado que lhe dá vantagens em eficiência. Tais limitações podem ter influência sobre a qualidade dos relacionamentos dos fornecedores públicos.

Soma-se a isto, o fato de que as pesquisas relativas às compras têm sido dominadas pelo setor de manufatura da iniciativa privada, limitando a aplicabilidade do conhecimento gerado por empresas no setor de serviços e no setor público (ZHENG et al., 2007).

É neste contexto que se apresenta o presente trabalho. O mesmo, a luz das dimensões da Qualidade de Relacionamento entre Empresas propostas por Holmlund (1997), busca identificar as especificidades que compõem a qualidade do relacionamento entre um órgão público e seus fornecedores privados. O trabalho analisa as especificidades na qualidade do relacionamento entre um órgão público (Intendência da Cidade Administrativa de Minas Gerais) e seus fornecedores privados na área de facilities.

Para tanto, o trabalho está dividido em cinco seções, incluída a seção atual. A segunda seção aponta aspectos relacionados à Qualidade Percebida de Relacionamento. Descreve o modelo de referência que será utilizado no trabalho para identificar as dimensões que formam à Qualidade Percebida de Relacionamento.

Na terceira seção, o método de pesquisa, a unidade de análise e as etapas são expostos.

Na quarta seção, os resultados obtidos nas quatro etapas da pesquisa são descritos e analisados.

Na quinta seção, faz-se uma discussão geral dos resultados encontrados.

Finalmente, na sexta seção, algumas considerações acerca dos resultados encontrados são tecidas. Além disso, uma limitação do trabalho é apontada. 


\section{REFERENCIAL TEÓRICO - QUALIDADE PERCEBIDA DE RELACIONAMENTO}

É fato que a qualidade é um daqueles conceitos fáceis de visualizar, mas extremamente difíceis de definir (GARVIN, 1984). Numa tentativa de compreender este termo, Garvin (1984) concluiu que a palavra qualidade apresenta diferentes significados para as pessoas, variando conforme o contexto. Nesta direção, este autor identificou cinco abordagens acerca do seu significado, são elas: i) Transcendente: nesta visão qualidade é sinônimo de excelência inata: uma marca de padrões firmes e alta realização; ii) Baseada no produto: esta considera a qualidade uma variável precisa e mensurável e afirma que diferenças nela refletem diferenças na quantidade de um componente ou atributo que o produto apresenta; iii)Baseada no usuário: parte da premissa de que a qualidade está nos olhos de quem vê e leva em conta que clientes diferentes têm desejos e necessidades diferenciados; iv) Baseada na manufatura: focaliza o atendimento às especificações desenvolvidas internamente durante o projeto; e v) Baseadas em valor: estabelece a qualidade em termos de valor e preço.

Holmlund (1997) apresenta quatro diferentes perspectivas que facilitam a conceituação do termo: a qualidade orientada à produção; a qualidade de serviços; a qualidade de relacionamento; e a qualidade de rede. Pode-se afirmar que tais perspectivas são complementares entre si e não são mutuamente excludentes. A qualidade nos relacionamentos tem como referência os relacionamentos de uma organização com os seus clientes e fornecedores.

A qualidade de relacionamento é um construto que surgiu a partir das pesquisas de qualidade de serviço. Este trata da "dinâmica da formação de qualidade de longo prazo em relacionamentos contínuos com os clientes"(GRÖNROOS, 2009). A qualidade de relacionamentos considera os processos de criação de valor do cliente ou do fornecedor, representando, assim, um escopo mais amplo do que a perspectiva de qualidade de serviços (HOLMLUND, 2007).

Mais importante do que a amplitude do escopo, esta perspectiva representa uma nova visão sobre o gerenciamento de qualidade, se comparado às perspectivas anteriores. O foco deixa de ser o produto como um bem ou um serviço, ou ainda o 
processo de produção de cada organização, passando a focar nas atividades que ocorrem na relação diádica entre os parceiros (HOLMLUND, 2007).

Grönroos (2009), de forma semelhante, destaca a interação como o conceito principal em qualquer relacionamento comercial entre duas partes. Segundo ele, as “interações são o fenômeno básico na qualidade e na formação de valor". Colocar a interação no centro da questão evidencia uma das preocupações dos defensores da qualidade de relacionamento: enfocar ambos os lados do processo. Isso é dizer que, como um relacionamento envolve ao menos dois atores, a qualidade é percebida em ambos os lados da interação.

Este processo de interação apresenta vários níveis. Tais níveis, hierarquizados entre si, são denominados atos, episódios e sequências, que constituem o relacionamento. Os atos seriam a menor unidade de análise, que em conjunto com outros atos inter-relacionados formam episódios. Exemplo de atos poderiam ser uma ligação telefônica ou uma visita. Os episódios são então conjuntos de atos e podem ser chamados de encontros de serviços. Como exemplo de episódios podem-se citar processos de negociação que envolvem diversos atos. Os episódios, quando relacionados a outros episódios formam sequências, que tem como característica uma perduração maior no tempo, tais como campanhas, projetos ou produtos. A agregação de sequências, por sua vez, formaria, por fim, o relacionamento (HOLMLUND, 1997).

A percepção de qualidade no nível menos agregado, o nível dos atos, influencia a percepção de qualidade do nível seguinte, os episódios, e assim por diante, passando pelas sequências até o nível do relacionamento (GRÖNROOS, 2009). Os diferentes níveis de interação em um relacionamento podem ser visualizados na Figura 1, a seguir. 
Figura 1 - Diferentes níveis de interação em um relacionamento.
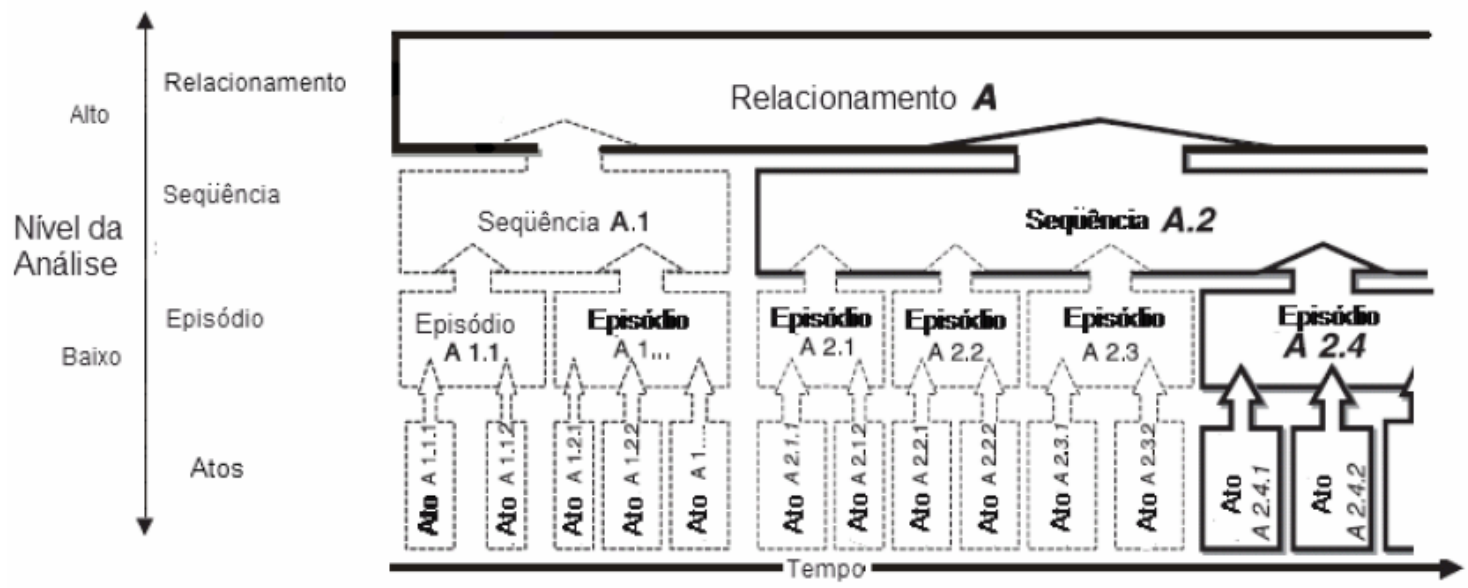

Fonte: HOLMLUND (2004)

As interações entre empresas ocorrem no menor nível, o nível dos atos. Essas interações são compostas de trocas e ajustes entre indivíduos das duas organizações. As experiências desses indivíduos no âmbito do relacionamento entre organizações são comparadas com padrões de relacionamentos. A comparação da experiência com os padrões de relacionamento leva à qualidade de relacionamento percebida no nível do indivíduo. Uma representação gráfica destas interações pode ser vista na Figura 2, a seguir (HOLMLUND, 1997).

Figura 2 - Domínios e dimensões das trocas e ajustes entre vendedor e comprador Interações

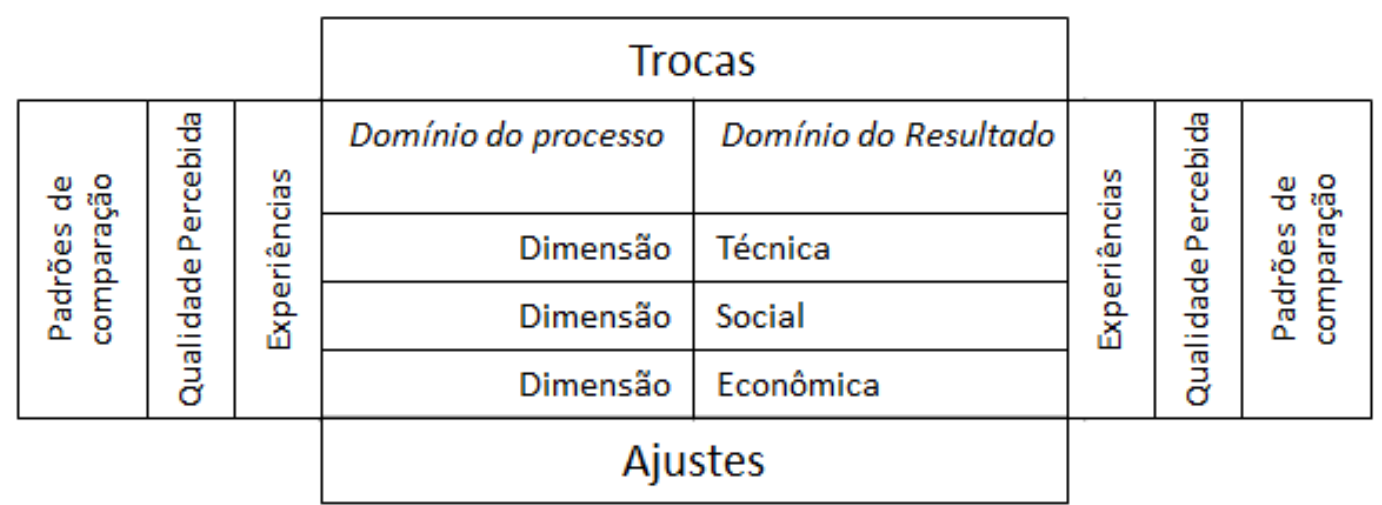

Vendedor

Comprador

Fonte: HOLMLUND (1997, p. 154)

Revista Produção Online, Florianópolis, SC, v.15, n. 4, p. 1426-1456, out./dez. 2015. 
A qualidade é percebida pelo indivíduo em sua experiência no nível do ato, e refere-se aos aspectos de processo e de resultado de uma interação em um relacionamento de serviços. O conteúdo específico das avaliações de qualidade engloba todos os tipos de interações no relacionamento, desde o objeto sendo ofertado, passando por aspectos sociais e até componentes financeiros. Esses tipos de conteúdo são classificados em dimensões técnica, social e econômica, que ocorrem tanto no domínio do processo quanto no domínio do resultado.

O domínio do processo diz respeito às percepções relativas a aspectos processuais em diferentes níveis de processo, em uma perspectiva processual de relacionamentos. Nessa mesma perspectiva, o domínio do resultado diz respeito às percepções dos resultados dos processos, também em diferentes níveis de interação.

A dimensão técnica "refere-se a um grupo de percepções de qualidade que concerne à essência do serviço ofertado no processo de criação de valor no relacionamento" (HOLMLUND, 1997, p. 108). No domínio do processo, a dimensão técnica abarca os tipos de composição de processos no relacionamento onde a oferta é construída: desenho, produção, gestão de estoque, entrega, manutenção e recuperação. Já no domínio de resultados estão presentes a confiabilidade, a inovação, a conformidade à estética e a durabilidade.

A dimensão social abarca um grupo de percepções de qualidade relativas às interações sociais no nível individual e organizacional. Esta dimensão, no domínio do processo, é caracterizada pela presença de confiança, atratividade, conhecimento, respeito, prazer e harmonia. No domínio de resultado, no nível individual, os elementos repetem-se: confiança, atratividade, conhecimento, respeito, prazer e harmonia. Já no nível da organização, a dimensão social é caracterizada neste domínio por coesão entre organizações, atração e confiança.

Por fim, a dimensão econômica diz respeito a um grupo de percepções de qualidade pertencente a diferentes questões econômicas, sejam elas ligadas a benefícios ou a custos de um relacionamento. Esta dimensão, no domínio de processo, é caracterizada pelas questões econômicas correntes no relacionamento tais como precificação, custos e produtividade. Já no domínio de resultados, há tanto os elementos de benefícios e dos custos do relacionamento. No lado dos benefícios 
há o nível de preço competitivo, o volume, a margem de lucro, a melhoria de produtividade, as premiações latentes de relacionamento. Quanto aos custos, estão presentes os custos diretos, indiretos e latentes de relacionamento (HOLMLUND, 1997).

Holmlund (1997) propõe um modelo completo de qualidade de relacionamento percebida, englobando os níveis (FIGURA 1), os domínios e as dimensões das interações (FIGURA 2), como se pode ver na Figura 3 a seguir.

Nesta representação, os hexágonos representam diferentes pessoas de cada organização, representada por elipses. As interações ocorrem por meio de experiências que, comparadas a padrões internalizados geram a qualidade percebida. Esta qualidade é analisada nos domínios de processo e de resultado, nas dimensões técnica, social e econômica. O conjunto de experiências de pessoas resultaria na experiência organizacional. O relacionamento seria um conjunto de sequências, que por sua vez são episódios agrupados, que, por fim são formados por atos.

Figura 3 - Modelo de qualidade percebida de relacionamento

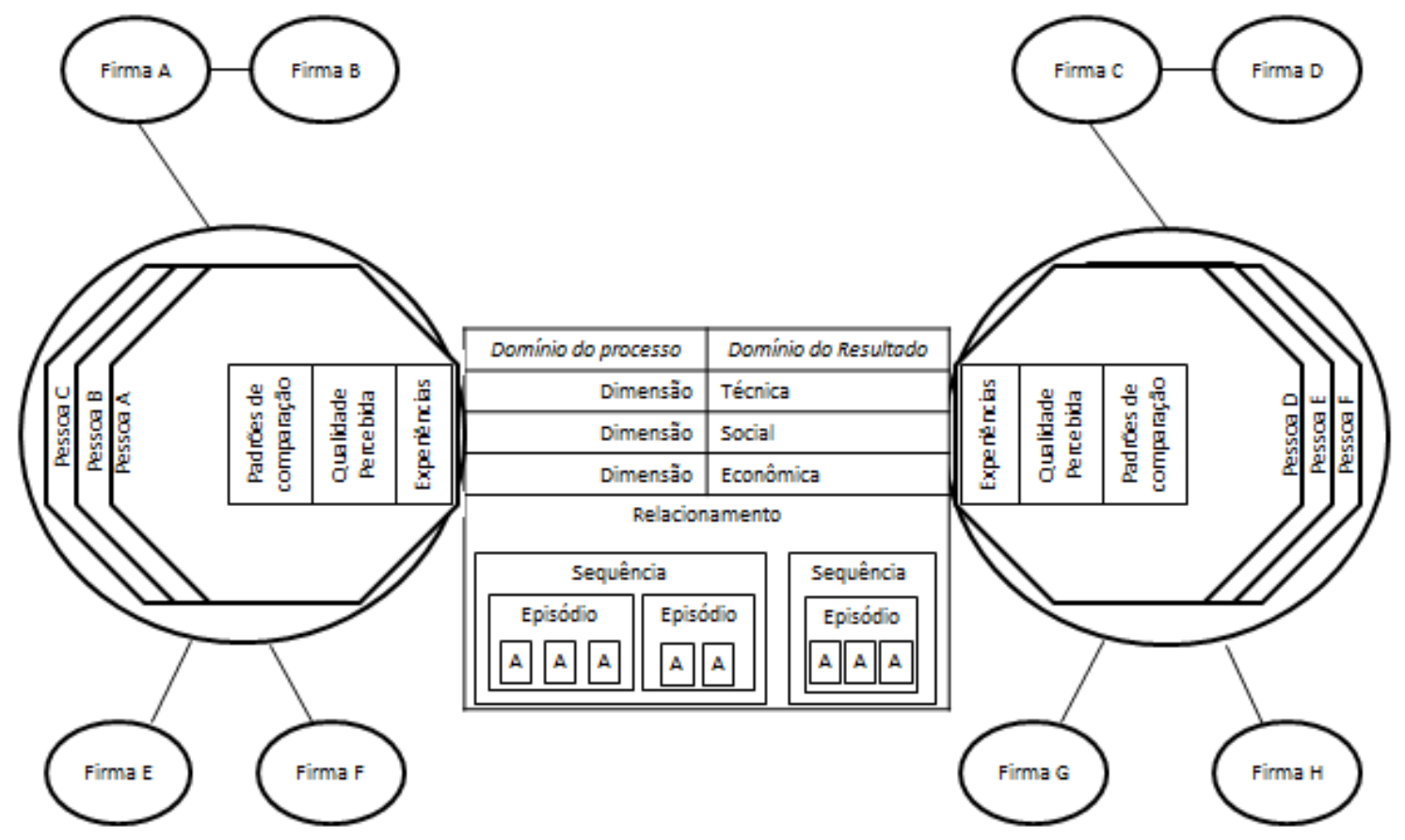

Fonte: (HOLMLUND, 1997, p. 162) 
Qualidade percebida de relacionamento seria então "a avaliação cognitiva conjunta de interações de negócio por indivíduos relevantes em ambas as firmas de díade. A avaliação abarca a comparação com interações alternativas potenciais de um tipo similar que representa padrões de comparação" (HOLMLUND, 1997, p. 9).

A presente pesquisa apoia-se nos construtos acima descritos, a saber: dimensão técnica, dimensão social, dimensão econômica, relacionamento, qualidade percebida de relacionamento, domínio do processo e domínio do resultado.

\section{MATERIAL E MÉTODO DA PESQUISA}

O método de pesquisa utilizado foi o estudo de caso. A escolha deste método foi feita porque o mesmo é adequado para se compreender um fenômeno contemporâneo dentro de seu contexto real, especialmente quando os limites entre o fenômeno e o contexto não estão claramente definidos (GERRING, 2004; MARTINS, 2006; YIN, 2001).

\subsection{Objeto de Estudo}

A organização foco do estudo é a Cidade Administrativa Presidente Tancredo Neves (CA). Esta iniciou a suas atividades em fevereiro de 2010, propiciando a reunião de mais de 59 órgãos e entidades do Governo do estado, representados por cerca de 17 mil pessoas em um único local. A gestão de serviços administrativos que antes era realizada de forma esparsa, descentralizada, e em contratos de pequeno vulto passou a ser feita de forma concentrada, centralizada e em contratos de grande vulto celebrados, em geral com empresas de porte maior.

Os idealizadores da Cidade Administrativa verificaram que a amplitude do novo empreendimento traria dificuldades de gestão caso fossem mantidos métodos ultrapassados de gestão de fornecedores. Com vistas à modernização da relação do governo mineiro com seus fornecedores, foi proposta uma nova metodologia de gestão de contratos e de fornecedores.

Associada à gestão de facillities está a aplicação do Acordo de Nível de Serviço (ANS), que constitui sistema de avaliação objetiva e mensuração do desempenho dos serviços fornecidos ao Governo, segundo indicadores e

Revista Produção Online, Florianópolis, SC, v.15, n. 4, p. 1426-1456, out./dez. 2015. 
metas de qualidade. O ANS pode ser considerado uma prática inovadora na administração pública uma vez que de modo geral não é comum a sua presença nos contratos administrativos (BDMG; GOVERNO DE MINAS GERAIS, 2013, p. 235)

Nesta metodologia de utilização do Acordo de Nível de Serviço (ANS), o registro de ocorrências torna-se uma etapa sem a qual o pagamento não é realizado. Esta metodologia surge para tentar simplificar e agilizar o processo de responsabilização do fornecedor pela qualidade de sua execução. A utilização de ANS é percebida como um avanço na área de gestão de fornecedores do setor público, seja por conta da possibilidade de averiguação de qualidade de serviços ou ainda por substituir processos administrativos punitivos morosos e ineficientes.

\subsection{Etapas da Pesquisa - Passo a passo}

A pesquisa foi conduzida em quatro etapas. A primeira etapa consistiu no levantamento de dados primários de execução dos indicadores de nível de serviço de contratos e sua análise. Esta etapa teve como finalidade conhecer a dinâmica empregada pelo Acordo de Nível de Serviço. Os pesquisadores também escolheram o serviço contratado que seria o objeto específico para o estudo de caso, a saber, o serviço de reprografia e impressão, pelos motivos que serão detalhados mais adiante.

A segunda etapa envolveu o uso da Técnica do Incidente Crítico (BITNER; BOOMS; TETREAULT, 1990; FLANAGAN, 1954; HAYES, 2001) para a identificação das necessidades dos clientes relativas ao serviço escolhido. Nesta etapa, 22 usuários foram entrevistados.

Os resultados da Técnica do Incidente Crítico apoiaram a construção de um survey (HAYES, 2001) que foi utilizado na terceira etapa da pesquisa. Este instrumento coletou a percepção da qualidade dos serviços prestados pelo fornecedor avaliado. Vários usuários participaram deste levantamento que contou com 964 respondentes, de um universo de possíveis 15000 (quinze mil)

A quarta etapa consistiu em entrevistas semiestruturadas, também baseadas na Técnica do Incidente Crítico, com os diversos gestores do serviço analisado, com o intuito de levantar informações quanto à qualidade de relacionamento entre o 
contratante (Intendência da Cidade Administrativa de Minas Gerais) e as empresas contratadas.

Durante cada uma das etapas, os dados levantados foram analisados à luz das dimensões (técnica, social e econômica) propostas pelo modelo de Holmlund (1997).

Apesar da literatura enfatizar que são as firmas, e não os indivíduos, que possuem relacionamentos de negócios, a importância dos indivíduos é ressaltada como atores relevantes, pois representam as interações, constituindo e formando os relacionamentos de negócio. Os relacionamentos não são determinados a priori, mudam e evoluem com o tempo e são protagonizados por equipes e empregados associados a diferentes papéis em ambas as empresas. As pessoas envolvidas no relacionamento como representantes da empresa são "as mais indicadas para prover informações sobre este relacionamento, uma vez que suas percepções e interpretações determinam o conteúdo e a orientação da díade" (HOLMLUND, 1997).

\section{RESULTADOS E ANÁLISE DE DADOS}

\subsection{Etapa 1 - Levantamento de dados de ANS e sua classificação}

O levantamento de dados primários de execução dos indicadores de nível de serviço de contratos e sua análise foram feitos nesta etapa. Vinte e sete contratos e seus respectivos 99 indicadores que compõem o ANS foram analisados. Verificou-se que dos 99 indicadores, 40 são relativos ao domínio do processo, e os demais 59 encontram-se no domínio do resultado. Quanto às dimensões, 94 indicadores estão classificados na dimensão técnica, 4 na dimensão social e apenas 1 na dimensão econômica, como pode ser visto no quadro abaixo 
Quadro 4.1 - Contratos, indicadores e sua classificação

OBJETO DO CONTRATO
Central de serviços de suporte
em microinformática

DESCRIÇÃO DO INDICADOR

(continua) em microinformática

Índice de solicitações atendidas no prazo $\quad$ P/T

especificado

Índice de solicitações resolvidas no prazo $\quad$ P/T

especificado

Índice de Disponibilidade do Portal Web de $\quad$ P/T

Atendimento

Índice de Disponibilidade da URA P/T

Tempo Médio de Espera para Atendimento $\quad \mathrm{P} / \mathrm{T}$

Telefônico

\begin{tabular}{ll}
\hline Taxa de Abandono & $\mathrm{P} / \mathrm{T}$ \\
\hline Tempo Médio de Espera para Atendimentos via & $\mathrm{P} / \mathrm{T}$
\end{tabular}

Web

Tempo Médio de Atendimento 1o nível $\quad$ P/T

Tempo Médio de Atendimento 2o nível $\quad \mathrm{P} / \mathrm{T}$

Índice de Resolução de Incidentes no 1o Nível $\quad$ R/T

(em \%)

Índice de Satisfação do usuário com o Serviço R/S

Prestado

Concessão de espaço para

exploração do serviço de

Ocorrências de retenção de dinheiro sem $\quad$ P/T

vendas de lanches e bebidas

frias por máquinas de

conveniência entregar produto

Concessão onerosa de uso de

Prazo de devolução de dinheiro retido nas

$\mathrm{P} / \mathrm{T}$

máquinas

Prazo de Validade dos Produtos ofertados $\quad$ R/T

Concessão onerosa de uso de espaço do primeiro pavimento

Satisfação dos clientes quanto aos serviços $\quad$ R/S

do Centro de Convivência para prestados

exploração de restaurante

Controle de pragas

Atendimento às normas sanitárias $\quad \mathrm{P} / \mathrm{T}$

Ocorrências de insetos e pragas nas áreas $\quad \mathrm{R} / \mathrm{T}$

Gerais Comuns da Cidade Administrativa

Ocorrências de insetos e pragas nas áreas de $\quad R / T$

Alimentação

Ocorrências de Roedores nas salas de Telecom e R/T

Subestações de Energia

Hospedagem de sistemas $\quad$ Disponibilidade da infraestrutura de hospedagem $\quad R / T$

no Data Center Outros dias e horários

Disponibilidade da infraestrutura de hospedagem $\mathrm{R} / \mathrm{T}$

no Data Center Horário Comercial

Hospedagem solução Microsoft $\quad$ Disponibilidade da infraestrutura de hospedagem $\quad$ R/T

no Data Center Horário Comercial

Disponibilidade da infraestrutura de hospedagem $\mathrm{R} / \mathrm{T}$

no Data Center Outros dias e horários

Disponibilidade da infraestrutura de hospedagem $\mathrm{R} / \mathrm{T}$

na CAMG Horário Comercial

Disponibilidade da infraestrutura de hospedagem $\mathrm{R} / \mathrm{T}$

na CAMG em Outros dias e horários

Infraestrutura de rede para

Disponibilidade do acesso à Internet

acesso à internet - conexão alta

disponibilidade

Disponibilidade da rede central (backbone) da $\quad R / T$ CONTRATADA

Instalação de equipamentos de Cumprimento dos prazos para fornecimento dos $\quad$ P/T

CFTV, acesso e controle de Equipamentos e Softwares estipulados na

ponto

Autorização de fornecimento

Revista Produção Online, Florianópolis, SC, v.15, n. 4, p. 1426-1456, out./dez. 2015. 
Quadro 4.1 - Contratos, indicadores e sua classificação

\begin{tabular}{|c|c|c|}
\hline OBJETO DO CONTRATO & DESCRIÇÃO DO INDICADOR & D\&D \\
\hline \multirow[t]{2}{*}{ Limpeza interna e externa da CA } & $\begin{array}{l}\text { Qualidade dos Aspectos Técnicos e de } \\
\text { Segurança do Serviço de Limpeza. }\end{array}$ & $\mathrm{R} / \mathrm{T}$ \\
\hline & Qualidade Efetiva dos Serviços de Limpeza & $R / T$ \\
\hline \multirow[t]{2}{*}{ Locação de banheiros químicos } & Limpezas semanais de 02 banheiros químicos. & $\mathrm{R} / \mathrm{T}$ \\
\hline & Limpezas avulsas de banheiros químicos. & $\mathrm{R} / \mathrm{T}$ \\
\hline \multirow{3}{*}{$\begin{array}{l}\text { Manutenção civil, predial e } \\
\text { hidráulica dos prédios e } \\
\text { sistemas da CA }\end{array}$} & Corretivas fechadas dentro do ANS & $\mathrm{R} / \mathrm{T}$ \\
\hline & Preventivas realizadas & $\mathrm{R} / \mathrm{T}$ \\
\hline & PE - Produtos Entregues & $\mathrm{R} / \mathrm{T}$ \\
\hline \multirow{4}{*}{$\begin{array}{l}\text { Manutenção de elevadores e } \\
\text { plataforma vertical }\end{array}$} & OS's corretivas fechadas no prazo & $\mathrm{P} / \mathrm{T}$ \\
\hline & OS's preventivas realizadas & $\mathrm{P} / \mathrm{T}$ \\
\hline & OS's corretivas $X$ OS's preventivas & $\mathrm{P} / \mathrm{T}$ \\
\hline & Disponibilidade de equipamentos & $\mathrm{R} / \mathrm{T}$ \\
\hline $\begin{array}{l}\text { Manutenção de equipamentos } \\
\text { de CFTV, acesso e controle de } \\
\text { ponto }\end{array}$ & $\begin{array}{l}\text { Realização da manutenção preventiva } \\
\text { programada }\end{array}$ & $\mathrm{P} / \mathrm{T}$ \\
\hline \multirow[t]{11}{*}{$\begin{array}{l}\text { Manutenção dos jardins e } \\
\text { paisagismo }\end{array}$} & $\begin{array}{l}\text { Se o projeto paisagístico original está sendo } \\
\text { seguido (espécies plantadas e formato dos } \\
\text { jardins nas especificações corretas, entre outros } \\
\text { requisitos). }\end{array}$ & $\mathrm{P} / \mathrm{T}$ \\
\hline & $\begin{array}{l}\text { Se todas as normas de segurança e/ou meio } \\
\text { ambiente estão sendo cumpridas. }\end{array}$ & $\mathrm{P} / \mathrm{T}$ \\
\hline & $\begin{array}{l}\text { Se o cronograma de atividades acordado entre } \\
\text { CONTRATANTE e CONTRATADA está sendo } \\
\text { cumprido. }\end{array}$ & $\mathrm{P} / \mathrm{T}$ \\
\hline & $\begin{array}{l}\text { Se as plantas apresentam boas condições } \\
\text { fitossanitárias, sem presença de insetos } \\
\text { predadores, doenças, desnutrição } \\
\text { (amarelecimento) e desidratação (ressecamento } \\
\text { ou murchamento). }\end{array}$ & $\mathrm{R} / \mathrm{T}$ \\
\hline & $\begin{array}{l}\text { Se os canteiros ou gramado estão livres de ervas } \\
\text { daninhas e/ou lixo. }\end{array}$ & $\mathrm{R} / \mathrm{T}$ \\
\hline & $\begin{array}{l}\text { Se a irrigação, tanto manual ou automática, está } \\
\text { sendo realizada de forma correta e na frequência } \\
\text { necessária em que todas as áreas necessárias. }\end{array}$ & $\mathrm{R} / \mathrm{T}$ \\
\hline & $\begin{array}{l}\text { Se a adubação e/ou poda e/ou corte da grama } \\
\text { e/ou capina/roçagem estão sendo realizados de } \\
\text { forma correta, na frequência necessária em todas } \\
\text { as áreas e plantas. }\end{array}$ & $\mathrm{R} / \mathrm{T}$ \\
\hline & $\begin{array}{l}\text { Se a limpeza em volta dos prédios e caminhos } \\
\text { (passeios) no gramado estão sendo realizadas } \\
\text { DIARIAMENTE e satisfatoriamente. }\end{array}$ & $\mathrm{R} / \mathrm{T}$ \\
\hline & $\begin{array}{l}\text { Se a limpeza das demais áreas está sendo } \\
\text { realizada satisfatoriamente. }\end{array}$ & $\mathrm{R} / \mathrm{T}$ \\
\hline & $\begin{array}{l}\text { Se as plantas que necessitam estão com as } \\
\text { escoras, tutores e/ou proteção de forma } \\
\text { adequada }\end{array}$ & $\mathrm{R} / \mathrm{T}$ \\
\hline & $\begin{array}{l}\text { Se os equipamentos estão sendo guardados e } \\
\text { não jogados nos gramados. }\end{array}$ & $\mathrm{P} / \mathrm{T}$ \\
\hline \multirow{2}{*}{$\begin{array}{l}\text { Manutenção dos sistemas de } \\
\text { prevenção e combate a incêndio }\end{array}$} & NOT - Notificações aplicadas & $\mathrm{P} / \mathrm{T}$ \\
\hline & PE - Produtos Entregues & $R / T$ \\
\hline
\end{tabular}

Revista Produção Online, Florianópolis, SC, v.15, n. 4, p. 1426-1456, out./dez. 2015. 
Quadro 4.1 - Contratos, indicadores e sua classificação

\begin{tabular}{|c|c|c|}
\hline OBJETO DO CONTRATO & DESCRIÇÃO DO INDICADOR & D\&D \\
\hline & Corretivas fechadas dentro do ANS & $\mathrm{P} / \mathrm{T}$ \\
\hline & Preventivas realizadas & $\mathrm{P} / \mathrm{T}$ \\
\hline & Disponibilidade de subsistemas críticos & $\mathrm{R} / \mathrm{T}$ \\
\hline \multirow{3}{*}{$\begin{array}{l}\text { Manutenção preventiva, } \\
\text { corretiva, inspeções e suporte } \\
\text { aos usuários nos equipamentos } \\
\text { de áudio e vídeo }\end{array}$} & Atendimento de prazos & $\mathrm{P} / \mathrm{T}$ \\
\hline & $\begin{array}{l}\text { Disponibilidade de ambientes / equipamentos - } \\
\text { Auditório e Palácio }\end{array}$ & $\mathrm{R} / \mathrm{T}$ \\
\hline & $\begin{array}{l}\text { Disponibilidade de ambientes / equipamentos - } \\
\text { demais ambientes }\end{array}$ & $\mathrm{R} / \mathrm{T}$ \\
\hline \multirow{3}{*}{$\begin{array}{l}\text { Provimento de infraestrutura de } \\
\text { rede e telefonia }\end{array}$} & Índice de solicitações resolvidas no prazo & $\mathrm{P} / \mathrm{T}$ \\
\hline & Disponibilidade do Serviço & $\mathrm{R} / \mathrm{T}$ \\
\hline & Índice de reclamações de atendimento & $\mathrm{R} / \mathrm{S}$ \\
\hline \multirow[t]{3}{*}{ Serviço de copeiros e garçons } & $\begin{array}{l}\text { Ocupação dos Postos de Trabalho Exigidos de } \\
\text { Copeira }\end{array}$ & $\mathrm{R} / \mathrm{T}$ \\
\hline & $\begin{array}{l}\text { Ocupação dos Postos de Trabalho Exigidos de } \\
\text { Garçom }\end{array}$ & $\mathrm{R} / \mathrm{T}$ \\
\hline & Qualidade dos Serviços & $R / T$ \\
\hline \multirow{3}{*}{$\begin{array}{l}\text { Serviço de fornecimento de café } \\
\text { e bebidas quentes por máquinas } \\
\text { de conveniência }\end{array}$} & Disponibilidade de equipamentos & $\mathrm{P} / \mathrm{T}$ \\
\hline & Devolução do dinheiro retido nas máquinas & $\mathrm{P} / \mathrm{T}$ \\
\hline & Dosimetria & $\mathrm{P} / \mathrm{T}$ \\
\hline \multirow{5}{*}{$\begin{array}{l}\text { Serviço de impressão e } \\
\text { reprografia }\end{array}$} & Tempo desobstrução de papel & $\mathrm{P} / \mathrm{T}$ \\
\hline & $\begin{array}{l}\text { Manutenção preventiva e troca de itens de } \\
\text { consumo }\end{array}$ & $\mathrm{P} / \mathrm{T}$ \\
\hline & Manutenção corretiva & $\mathrm{P} / \mathrm{T}$ \\
\hline & Disponibilidade de sistemas & $\mathrm{R} / \mathrm{T}$ \\
\hline & $\begin{array}{l}\text { Atendimento de serviços pelas centrais de } \\
\text { reprografia e impressão }\end{array}$ & $\mathrm{R} / \mathrm{T}$ \\
\hline \multirow[t]{5}{*}{ Serviço de recepção e vigilância } & $\begin{array}{l}\text { Ocupação dos Postos no serviço de recepção } \\
\text { Recepcionista }\end{array}$ & $\mathrm{R} / \mathrm{T}$ \\
\hline & Ocupação dos Postos no serviço de vigilância & $\mathrm{R} / \mathrm{T}$ \\
\hline & Qualidade dos Serviços de Recepção & $\mathrm{R} / \mathrm{T}$ \\
\hline & $\begin{array}{l}\text { Qualidade dos Serviços de Vigia Desarmada do } \\
\text { Patrimônio e de Pessoas }\end{array}$ & $\mathrm{R} / \mathrm{T}$ \\
\hline & Qualidade dos Serviços de Ronda Noturna & $\mathrm{R} / \mathrm{T}$ \\
\hline \multirow[t]{6}{*}{$\begin{array}{l}\text { Serviço de telefonia fixa } \\
\text { comutada }\end{array}$} & $\begin{array}{l}\text { Atraso na prestação de informações e } \\
\text { esclarecimentos solicitados pela Contratada } \\
\text { superior a } 48 \text { (quarenta e oito) horas. }\end{array}$ & $\mathrm{P} / \mathrm{T}$ \\
\hline & $\begin{array}{l}\text { Quebra do sigilo e inviolabilidade das } \\
\text { conversações realizadas através dos recursos } \\
\text { disponibilizados pela contratada }\end{array}$ & $\mathrm{P} / \mathrm{T}$ \\
\hline & $\begin{array}{l}\text { Interrupção da prestação do serviço. (a cada } 30 \\
\text { min.) }\end{array}$ & $\mathrm{R} / \mathrm{T}$ \\
\hline & $\begin{array}{l}\text { Não atendimento do telefone cujo número foi } \\
\text { fornecido pela Contratada para registro das } \\
\text { reclamações. }\end{array}$ & $\mathrm{P} / \mathrm{T}$ \\
\hline & Cobrança por serviços não prestados. & $\mathrm{R} / \mathrm{E}$ \\
\hline & $\begin{array}{l}\text { Envio das informações de tráfego contendo erros } \\
\text { de cálculos }\end{array}$ & $\mathrm{P} / \mathrm{T}$ \\
\hline
\end{tabular}

Revista Produção Online, Florianópolis, SC, v.15, n. 4, p. 1426-1456, out./dez. 2015. 


\begin{tabular}{|c|c|c|}
\hline & $\begin{array}{l}\text { Não atendimento às reclamações dentro dos } \\
\text { prazos estipulados pela a ANATEL }\end{array}$ & $\mathrm{P} / \mathrm{T}$ \\
\hline & $\begin{array}{l}\text { Não atendimento aos prazos de } 10 \text { (dez) dias } \\
\text { para solicitação de manutenção preventiva e aos } \\
\text { prazos definidos no item } 5.7 .6 \text { para reparo. }\end{array}$ & $\mathrm{P} / \mathrm{T}$ \\
\hline Serviço de telefonia móvel & Disponibilidade do Serviço & $\mathrm{R} / \mathrm{T}$ \\
\hline \multirow[t]{3}{*}{$\begin{array}{l}\text { Serviço de transporte de } \\
\text { passageiros por fretamento }\end{array}$} & $\begin{array}{l}\text { Frequência dos veículos/índice de atraso de } \\
\text { acordo com o planejado. }\end{array}$ & $\mathrm{R} / \mathrm{T}$ \\
\hline & Índice de acidentes. & $\mathrm{R} / \mathrm{T}$ \\
\hline & Índice de Satisfação do Usuário. & $\mathrm{R} / \mathrm{S}$ \\
\hline \multirow{3}{*}{$\begin{array}{l}\text { Serviço de vigia desarmada - } \\
\text { Vilarinho }\end{array}$} & Ocupação dos Postos no serviço de vigilância & $\mathrm{R} / \mathrm{T}$ \\
\hline & $\begin{array}{l}\text { Qualidade dos Serviços de Vigia Desarmada do } \\
\text { Patrimônio e de Pessoas }\end{array}$ & $\mathrm{R} / \mathrm{T}$ \\
\hline & Qualidade dos Serviços de Ronda Noturna & $\mathrm{R} / \mathrm{T}$ \\
\hline \multirow{2}{*}{$\begin{array}{l}\text { Serviço médico de urgência e } \\
\text { emergência }\end{array}$} & Disponibilidade dos Postos de Trabalho & $\mathrm{R} / \mathrm{T}$ \\
\hline & Prontidão nos Atendimentos de Urgência & $\mathrm{R} / \mathrm{T}$ \\
\hline \multirow{4}{*}{$\begin{array}{l}\text { Suporte técnico, manutenção e } \\
\text { treinamento em MS Dynamics }\end{array}$} & Índice de OS de Manutenção concluídas no prazo & $\mathrm{P} / \mathrm{T}$ \\
\hline & $\begin{array}{l}\text { Índice de Chamados de Suporte atendidos no } \\
\text { prazo }\end{array}$ & $\mathrm{P} / \mathrm{T}$ \\
\hline & $\begin{array}{l}\text { Índice de Disponibilidade do sistema em horário } \\
\text { comercial da CA }\end{array}$ & $\mathrm{R} / \mathrm{T}$ \\
\hline & $\begin{array}{l}\text { Índice de Disponibilidade do sistema no horário } \\
\text { não comercial }\end{array}$ & $\mathrm{R} / \mathrm{T}$ \\
\hline
\end{tabular}

Fonte: elaborado pelos autores

\section{A escolha de um objeto}

Dentre os fornecedores e prestadores de serviço da Intendência da Cidade Administrativa, observou-se que havia dois cujo objeto de trabalho era o serviço de reprografia e impressão. Trata-se do único objeto em que havia um prestador para cada um dos dois principais prédios da Cidade Administrativa. De vulto considerável, na casa de centenas de milhares de reais mensais, estes contratos apresentavam regras idênticas, prazos de vigência muito próximos, mesma forma de medição de desempenho de ANS, mesmos gestores, mesmo quantitativo e tipo de cliente. A principal diferença entre os contratos é o local de prestação de serviços. Um era relativo ao edifício denominado "Minas", e o outro ao prédio "Gerais". Os prédios, vizinhos um do outro, são também idênticos entre si, na forma, no tamanho, na estrutura, e têm população de servidores bastante semelhante. Esta excepcionalidade permite a comparação entre duas empresas diferentes, que atuam Revista Produção Online, Florianópolis, SC, v.15, n. 4, p. 1426-1456, out./dez. 2015. 
frente a públicos semelhantes, com contratos idênticos geridos pelo mesmo contratante e por meio da mesma metodologia e indicadores de ANS. Por ser um caso raro, o estudo dos prestadores de serviço de reprografia e impressão da Cidade Administrativa proporciona a possibilidade de se realizar um estudo de caso único. Estes dois contratos foram escolhidos como objeto específico para o estudo de caso. Foram também coletados dados primários de execução de cinco indicadores destes fornecedores, pelo período de 24 meses, totalizando 240 medições de desempenho. Os indicadores analisados são os informados abaixo.

Quadro 4.2 - Indicadores dos contratos de reprografia e impressão

\begin{tabular}{|c|c|c|}
\hline Nome do indicador & Fórmula & Meta \\
\hline Obstrução de papel & $\begin{array}{l}\text { Total de chamados de obstrução de papel no } \\
\text { período fechados no prazo / Total de chamados } \\
\text { de obstrução de papel do período }\end{array}$ & $90 \%$ \\
\hline $\begin{array}{l}\text { Troca de itens de } \\
\text { consumo }\end{array}$ & $\begin{array}{l}\text { Total de chamados de troca de itens de consumo } \\
\text { no período fechados no prazo / Total de } \\
\text { chamados de troca de consumíveis do período }\end{array}$ & $90 \%$ \\
\hline $\begin{array}{l}\text { Consertos e/ou } \\
\text { substituição de } \\
\text { equipamentos }\end{array}$ & $\begin{array}{l}\text { Total de ordens de serviço corretivas do período } \\
\text { fechadas no prazo / Total de ordens de serviço } \\
\text { corretivas do período }\end{array}$ & $90 \%$ \\
\hline $\begin{array}{l}\text { Indisponibilidade dos } \\
\text { sistemas }\end{array}$ & $\begin{array}{l}\text { Somatório de disponibilidade dos sistemas } \\
\text { críticos / } 4 \text { (número de sistemas críticos) }\end{array}$ & $90 \%$ \\
\hline $\begin{array}{l}\text { Atendimento às ordens } \\
\text { de serviço pelas } \\
\text { centrais de reprografia }\end{array}$ & $\begin{array}{l}\text { Total de ordens de serviço do período fechadas } \\
\text { no prazo / Total de ordens de serviço do período }\end{array}$ & $90 \%$ \\
\hline
\end{tabular}

Fonte: Elaborado pelo autor a partir do contrato 893/2010

Não se verificou uma disparidade acentuada entre eles. Ambos os prestadores de serviço apresentaram um desempenho semelhante pela lógica do ANS. A lógica do ANS, no caso, é o nível de serviço acordado, ou seja, sua meta, que como pode ser observada na tabela acima é de $90 \%$ para todos os indicadores. Somente 1 (uma) de 240 (duzentas e quarenta) medições apontou um dado abaixo da meta. Ou seja, ambas as empresas tiveram resultados satisfatórios em mais de $99 \%$ dos casos. Os resultados da medição seguem na tabela abaixo. 
Tabela 4.1 - Resultado dos indicadores de reprografia impressão de janeiro de 2012 a dezembro de 2013 (em \%)

\begin{tabular}{|c|c|c|c|c|c|c|c|c|c|c|}
\hline \multirow{2}{*}{$\begin{array}{c}\text { Indicador } \\
\text { Período/Prédio }\end{array}$} & \multicolumn{2}{|c|}{$\begin{array}{c}\text { Tempo } \\
\text { desobstrução } \\
\text { de papel }\end{array}$} & \multicolumn{2}{|c|}{$\begin{array}{c}\text { Tempo de } \\
\text { troca de } \\
\text { itens de } \\
\text { consumo }\end{array}$} & \multicolumn{2}{|c|}{$\begin{array}{c}\text { Consertos } \\
\text { elou } \\
\text { substituição } \\
\text { de } \\
\text { equipamentos }\end{array}$} & \multicolumn{2}{|c|}{$\begin{array}{l}\text { Indisponibilidade } \\
\text { dos sistemas }\end{array}$} & \multicolumn{2}{|c|}{$\begin{array}{c}\text { Atendimento } \\
\text { às ordens } \\
\text { de serviço } \\
\text { pelas } \\
\text { centrais de } \\
\text { reprografia }\end{array}$} \\
\hline & P 1 & P 2 & P 1 & P 2 & P 1 & P 2 & P 1 & P 2 & P 1 & P 2 \\
\hline jan/12 & 100 & 100 & 100 & 100 & 100 & 100 & 100 & 100 & 100 & 100 \\
\hline fev/12 & 100 & 100 & 100 & 100 & 100 & 100 & 100 & 100 & 100 & 100 \\
\hline mar/12 & 100 & 100 & 100 & 100 & 100 & 100 & 100 & 100 & 100 & 100 \\
\hline $\mathrm{abr} / 12$ & 93,75 & 100 & 98,98 & 100 & 100 & 100 & 100 & 100 & 100 & 100 \\
\hline mai/12 & 100 & 100 & 100 & 100 & 97,53 & 100 & 86,02 & 100 & 100 & 100 \\
\hline jun/12 & 93,33 & 100 & 96,67 & 100 & 97,59 & 100 & 96,36 & 100 & 100 & 100 \\
\hline jul/12 & 100 & 100 & 100 & 100 & 100 & 100 & 100 & 100 & 100 & 100 \\
\hline ago/12 & 100 & 100 & 100 & 100 & 100 & 100 & 100 & 100 & 100 & 100 \\
\hline set/12 & 100 & 100 & 100 & 100 & 100 & 100 & 100 & 99,03 & 100 & 100 \\
\hline out/12 & 100 & 100 & 100 & 100 & 100 & 100 & 100 & 100 & 95,51 & 100 \\
\hline nov/12 & 100 & 100 & 100 & 100 & 100 & 100 & 100 & 100 & 100 & 100 \\
\hline dez/12 & 100 & 100 & 100 & 100 & 100 & 100 & 100 & 100 & 100 & 100 \\
\hline $\mathrm{jan} / 13$ & 100 & 100 & 100 & 100 & 100 & 100 & 100 & 100 & 100 & 100 \\
\hline $\mathrm{fev} / 13$ & 100 & 100 & 100 & 100 & 100 & 100 & 100 & 100 & 100 & 100 \\
\hline $\mathrm{mar} / 13$ & 100 & 100 & 100 & 100 & 100 & 100 & 100 & 100 & 100 & 100 \\
\hline $\mathrm{abr} / 13$ & 100 & 100 & 100 & 100 & 100 & 100 & 100 & 100 & 100 & 100 \\
\hline mai/13 & 100 & 100 & 100 & 100 & 100 & 100 & 100 & 100 & 100 & 100 \\
\hline jun/13 & 100 & 100 & 100 & 100 & 100 & 100 & 100 & 100 & 99,57 & 100 \\
\hline $\mathrm{jul} / 13$ & 100 & 100 & 100 & 100 & 98,21 & 100 & 100 & 100 & 100 & 100 \\
\hline ago/13 & 100 & 100 & 97,67 & 100 & 100 & 100 & 100 & 100 & 100 & 100 \\
\hline set/13 & 100 & 100 & 100 & 100 & 100 & 100 & 100 & 100 & 100 & 100 \\
\hline out/13 & 95 & 100 & 100 & 100 & 100 & 100 & 100 & 100 & 100 & 100 \\
\hline nov/13 & 100 & 100 & 100 & 100 & 100 & 100 & 100 & 100 & 100 & 100 \\
\hline dez/13 & 100 & 100 & 100 & 100 & 100 & 100 & 100 & 100 & 100 & 100 \\
\hline
\end{tabular}

Fonte: Elaborado pelo autor (2014)

Legenda: $\mathrm{P} 1$ = prédio $1 . \mathrm{P} 2=$ prédio 2.

\subsection{Etapa 2 - Pesquisa por novas dimensões de qualidade de serviço}

Com vistas a verificar a existência de dimensões de qualidade de serviço além das retratadas pelos indicadores de ANS existentes, procedeu-se a uma fase exploratória qualitativa denominada Técnica dos Incidentes Críticos (TIC). Incidentes são definidos como incidentes de interação percebidos ou lembrados pelos clientes como positivos ou negativos de forma não usual (EDVARDSSON; ROOS, 2001).

Revista Produção Online, Florianópolis, SC, v.15, n. 4, p. 1426-1456, out./dez. 2015. 
A TIC é uma "série de procedimentos para coletar observações diretas do comportamento humano de forma a facilitar sua utilidade potencial para resolução de problemas práticos" (FLANAGAN, 1954, p. 1). A TIC permite registrar eventos e comportamentos observados que levam ao sucesso ou ao fracasso de uma determinada tarefa, tal como satisfazer um cliente. Seu uso em pesquisas na área de serviços é muito difundido, tendo se tornado uma ferramenta para retratar a qualidade percebida e o nível de satisfação dos clientes (BITNER; BOOMS; TETREAULT, 1990; EDVARDSSON; ROOS, 2001).

Sua metodologia é composta de três fases. Na primeira fase ocorre o levantamento de incidentes críticos por meio de entrevistas com usuários. $\mathrm{Na}$ segunda os incidentes críticos são classificados em itens de satisfação e em necessidades dos clientes. Por fim, a terceira fase contempla um julgamento das classificações por dois juízes, a fim de validá-las (HAYES, 2001). Estas fases são detalhadas a seguir.

Figura 4.1 - Etapas da classificação de incidentes críticos

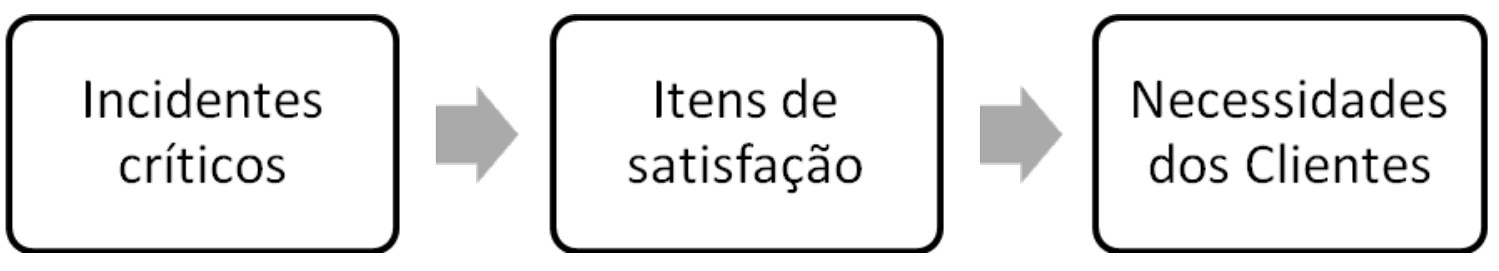

Fonte: Produzido pelo autor (2014). Baseado em Hayes (1996)

$\mathrm{Na}$ primeira fase, 40 clientes do serviço de reprografia foram convidados a preencher um formulário relatando até cinco incidentes críticos positivos e cinco incidentes críticos negativos. Após uma semana, 22 pessoas haviam respondido, obtendo-se, 81 incidentes negativos e 80 incidentes positivos.

A quantidade de incidentes críticos registrados foi considerada suficiente ao se utilizar o teste sugerido por Hayes (1996). Os incidentes críticos dos 19 primeiros respondentes foram classificados em itens de satisfação, enquanto os incidentes relatados pelos três últimos respondentes foram reservados. Após a classificação, procedeu-se ao trabalho de tentar enquadrar os itens dos três últimos respondentes nos itens de satisfação criados sobre os dos 19 primeiros. Todos os novos incidentes foram enquadrados, percebendo-se, assim, que novos incidentes não 
agregavam novos itens de satisfação, mas repetiam ocorrências anteriormente relatadas por outros clientes.

Três critérios de validade dos incidentes críticos foram utilizados: (i) envolver uma interação entre cliente e provedor; (ii) ser insatisfatório ou satisfatório do ponto de vista do cliente; (iii) haver detalhe suficiente para ser visualizado pelo interpretador (BITNER; BOOMS; MOHR, 1994). A princípio, nem todos os incidentes relatados atendiam aos critérios propostos. Contudo, nova entrevista foi realizada com os respondentes cujo incidente suscitou dúvida, a fim de gerar esclarecimento e permitir ao máximo que os incidentes tornassem-se válidos para a pesquisa. Ao final, dos 161 incidentes críticos inicialmente registrados, 159 foram considerados válidos e dois foram descartados por não atenderem aos critérios acima.

$\mathrm{Na}$ segunda fase, os incidentes críticos, cuja uma amostra foi transcrita acima, foram agrupados e traduzidos em itens de satisfação. Neste momento, criaram-se 61 itens de satisfação para os 159 incidentes críticos considerados válidos. Estes itens de satisfação foram então classificados em oito necessidades dos clientes, a saber: confiabilidade, cordialidade do atendimento, disponibilidade do serviço, economia de recursos, informações claras e precisas, praticidade, resultado estético e, por fim, velocidade e pontualidade.

$\mathrm{Na}$ terceira fase, realizaram-se dois julgamentos das classificações do pesquisador por duas pessoas independentes, que atuaram como juízes (HAYES, 2001). Nesta fase, uma primeira juíza foi convidada a aferir a classificação inicialmente proposta. Foi escolhida como juíza a Diretora de Gestão de Contratos e Convênios da Intendência da Cidade Administrativa, por seu conhecimento sobre gestão de fornecedores e de contratos, bem como sobre os serviços de reprografia e a impressão.

A esta primeira juíza foram apresentados inicialmente todos os incidentes críticos embaralhados, e foi solicitado que se classificasse novamente cada incidente crítico frente a um item de satisfação anteriormente criado. Houve uma correspondência de $92 \%$ entre a classificação inicial e a realizada pela primeira juíza. Este índice é considerado alto, por estar acima de 80\% (HAYES, 1996). Ainda assim, os 8\% restantes foram reclassificados em comum acordo entre o pesquisador e a primeira juíza, após diálogos sobre os seus significados. 
Em seguida, a primeira juíza enquadrou cada um dos itens de satisfação dentre as necessidades dos clientes anteriormente criadas. Conforme metodologia sugerida por Bitner, Booms e Mohr (1994), foi dado à juíza a possibilidade de não classificar os itens de satisfação que ela julgasse não pertencer a nenhuma das categorias de necessidades dos clientes. Contudo, nenhum dos itens ficou sem classificação, havendo concordância de que as necessidades dos clientes criadas abrangiam todo o conteúdo dos incidentes críticos. Este segundo julgamento, do enquadramento dos itens de satisfação em necessidades de clientes, obteve uma correspondência de $85 \%$ entre o pesquisador e a primeira juíza. Os $15 \%$ restantes foram reclassificados após diálogo entre o classificador e a primeira juíza, até que houvesse consenso.

Obtido consenso entre pesquisador e primeira juíza, uma segunda juíza foi convidada a participar do processo. Foi selecionada para a função a Subintendente de Aquisições e Contratações da Intendência da Cidade Administrativa, também por seu conhecimento sobre gestão de fornecedores e de contratos, bem como sobre os serviços de reprografia e a impressão. Foi-lhe solicitado que, sem conhecer os enquadramentos anteriores, classificasse diretamente os incidentes críticos em necessidades dos clientes, saltando os itens de satisfação. Houve equivalência de 87\% entre o julgamento da segunda juíza e a classificação anterior, nível considerado alto, conforme os autores da área (BITNER; BOOMS; MOHR, 1994; HAYES, 2001).

Os resultados da TIC estão apresentados na Tabela 1. As necessidades dos clientes que mais sobressaíram nesta etapa foram a praticidade, a confiabilidade e a velocidade, quando se consideram incidentes positivos e negativos. Dentre os positivos, destacaram-se a praticidade, a velocidade e a economia. Já nos negativos, destaque para a confiabilidade, a velocidade e a praticidade. 
Tabela 1 - Classificação dos incidentes críticos em necessidades dos clientes

\begin{tabular}{llllllllc}
\hline & \multicolumn{3}{c}{$\begin{array}{c}\text { Incidente Crítico } \\
\text { Positivo }\end{array}$} & \multicolumn{2}{c}{ Negativo } & \multicolumn{2}{c}{ Total } & \multicolumn{2}{c}{$\begin{array}{c}\text { Itens de } \\
\text { Satisfação } \\
\text { Total }\end{array}$} \\
\hline Necessidade & $\mathrm{N}^{\circ}$ & $\%$ & $\mathrm{~N}^{\circ}$ & $\%$ & $\mathrm{~N}^{\circ}$ & $\%$ & $\mathrm{~N}^{\circ}$ & $\%$ \\
Confiabilidade & 4 & $12 \%$ & 29 & $88 \%$ & 33 & $21 \%$ & 11 & $18 \%$ \\
Cordialidade & 5 & $100 \%$ & 0 & $0 \%$ & 5 & $3 \%$ & 2 & $3 \%$ \\
Disponibilidade & 4 & $36 \%$ & 7 & $64 \%$ & 11 & $7 \%$ & 7 & $11 \%$ \\
Economia & 12 & $92 \%$ & 1 & $8 \%$ & 13 & $8 \%$ & 4 & $7 \%$ \\
Informações claras & 0 & $0 \%$ & 6 & $100 \%$ & 6 & $4 \%$ & 3 & $5 \%$ \\
Praticidade & 29 & $64 \%$ & 16 & $36 \%$ & 45 & $28 \%$ & 19 & $31 \%$ \\
Resultado estético & 11 & $73 \%$ & 4 & $27 \%$ & 15 & $9 \%$ & 4 & $7 \%$ \\
Velocidade & 13 & $42 \%$ & 18 & $58 \%$ & 31 & $19 \%$ & 11 & $18 \%$ \\
Total & 78 & $49 \%$ & 81 & $51 \%$ & 159 & $100 \%$ & 61 & $100 \%$ \\
\hline
\end{tabular}

Fonte: Elaborado pelo autor (2014)

As necessidades dos clientes levantadas foram classificadas quanto às dimensões propostas por Holmlund (1997). Como se pode verificar na Tabela 2 abaixo, ocorre uma predominância da dimensão técnica, com 90\% dos itens de satisfação. A dimensão econômica vem em seguida da ordem de relevância, com $7 \%$. Por fim, a dimensão social surge com 3\% dos itens de satisfação.

Tabela 2 - Classificação das necessidades dos clientes em dimensões

\begin{tabular}{lrccc}
\hline Necessidades & $\mathbf{n}^{\mathbf{0}}$ & Dimensão & $\mathbf{n}^{\mathbf{0}}$ & $\%$ \\
\hline Economia & 4 & Econômica & 4 & $7 \%$ \\
Cordialidade & 2 & Social & 2 & $3 \%$ \\
Confiabilidade & 11 & & & \\
$\begin{array}{l}\text { Disponibilidade } \\
\text { Informações }\end{array}$ & 7 & & & \\
claras & 3 & Técnica & 55 & $90 \%$ \\
$\begin{array}{l}\text { Praticidade } \\
\text { Resultado }\end{array}$ & 19 & & & \\
estético & 4 & & \\
Velocidade & 11 & & \\
Fonte: Elaborada pelo autor (2014)
\end{tabular}

\subsection{Etapa 3 - Survey}

Seguindo a metodologia proposta do Hayes (1996), foi estruturado um survey com os itens de satisfação levantados pelo TIC. Este survey consistiu de 61 
afirmações às quais o respondente deveria indicar seu nível de discordância ou concordância em uma escala Likert de 7 pontos.

O survey foi estruturado em uma plataforma eletrônica e enviado por correio eletrônico para aproximadamente 17.000 contas de usuários cadastrados na Cidade Administrativa (CA). Destes, 3480 não atingiram o destinatário. Os principais motivos foram: caixa cheia, aviso automático de período de férias, usuário desligado da instituição e erro no cadastramento do e-mail junto ao sistema de usuários da CA.

A despeito dos resultados apontados pelo ANS não indicarem uma diferença significativa de desempenho entre os dois fornecedores analisados, a pesquisa do survey apontou uma diferença de desempenho entre eles. Verificou-se que 37 dos 61 itens pesquisados apresentaram diferenças estatisticamente significativas entre as médias.

Esta etapa apontou a existência de outras dimensões de qualidade sob a ótica dos usuários, além das já definidas contratualmente. Por meio da Técnica do Incidente Crítico, verificou-se a existência de oito necessidades dos clientes, seis a mais que as necessidades cobertas pelos indicadores de ANS do contrato. As necessidades elencadas não previstas anteriormente são a confiabilidade, a cordialidade, a economia de recursos, as informações claras e precisas, a praticidade e o resultado estético.

Quanto à classificação das necessidades dos clientes em dimensões de qualidade, novamente houve predomínio da dimensão técnica, com 90\% dos incidentes críticos relativos a esta dimensão. As dimensões econômica e social ocorreram, embora de forma menos expressiva, representando $7 \%$ e $3 \%$ respectivamente.

A predominância da dimensão técnica sobre as demais pode ser explicada em parte pelo estreito escopo de atuação dos usuários finais no processo de relacionamento com fornecedor.

Deve-se levar em conta também o alto grau de automatização do serviço pesquisado, gerando pouca interação humana no andamento normal do serviço de impressão. As oportunidades de contato entre usuários e funcionários da prestadora de serviço ocorrem no serviço de reprografia de itens mais volumosos e que exigem 
encadernação, formatos especiais e cores, ou ainda na recuperação de serviços, quando surgem falhas na execução ordinária.

\section{4 - Etapa 4 - Incidentes críticos de qualidade de relacionamento}

Nesta etapa, utilizou-se novamente a TIC em entrevistas com os gestores da Intendência da Cidade Administrativa - órgão público que gerencia os serviços de facilities do complexo responsável pelos contratos de reprografia e impressão. Cinco gestores de atribuições diferentes relativas ao prestador de serviços foram entrevistados. Após o levantamento, os incidentes críticos foram agrupados em itens de satisfação e posteriormente em necessidades dos clientes.

$\mathrm{Na}$ classificação de itens de satisfação em necessidades dos clientes, tomouse o cuidado, de tentar, primeiramente, não criar novas categorias além daquelas já elencadas quando da etapa 2 junto aos usuários finais. Contudo, alguns itens de satisfação ficaram sem classificação, forçando a se admitir que havia novas necessidades de clientes. São elas: a flexibilidade financeira, o atendimento profissional, a flexibilidade de gestão, a inovação e a segurança jurídica. Das necessidades dos clientes que já haviam sido detectadas na etapa 2, ressurgiram na presente etapa: economia de recursos, cordialidade, confiabilidade, disponibilidade, informações claras e precisas, praticidade, e, por fim, velocidade e pontualidade. O Quadro 1 a seguir relaciona as dimensões existentes com as necessidades dos clientes e os itens de satisfação, mostrando, para cada categoria o número de ocorrências em valores absolutos e relativos.

Revista Produção Online, Florianópolis, SC, v.15, n. 4, p. 1426-1456, out./dez. 2015. 
Quadro 1 - Dimensões, necessidades dos clientes e itens de satisfação

\begin{tabular}{|c|c|c|c|c|c|c|c|c|}
\hline Dimensão & $\mathrm{n}^{0}$ & $\%$ & \begin{tabular}{|l|}
$\begin{array}{l}\text { Necessidade dos } \\
\text { Clientes }\end{array}$ \\
\end{tabular} & $n^{0}$ & $\%$ & Item de satisfação & $\mathrm{n}^{\circ}$ & $\%$ \\
\hline \multirow{3}{*}{ Econômica } & \multirow{3}{*}{13} & \multirow{3}{*}{$21 \%$} & & \multirow[b]{2}{*}{12} & \multirow[b]{2}{*}{$19 \%$} & $\begin{array}{l}\text { Há flexibilidade de prorrogaçáo de notas fiscais quando } \\
\text { demandado. }\end{array}$ & 5 & $8 \%$ \\
\hline & & & $\begin{array}{l}\text { Flexibilidade } \\
\text { financeira }\end{array}$ & & & $\begin{array}{l}\text { Ha flexıbilidade quanto a eventual prestação de serviços } \\
\text { afins não previstos contratualmente, sem custos extras para } \\
\text { o contratante. }\end{array}$ & 7 & $11 \%$ \\
\hline & & & $\begin{array}{l}\text { Economia de } \\
\text { recursos }\end{array}$ & 1 & $2 \%$ & O custo é baixo. & 1 & $2 \%$ \\
\hline \multirow{7}{*}{ Social } & \multirow{7}{*}{12} & \multirow{7}{*}{$19 \%$} & \multirow{3}{*}{$\begin{array}{l}\text { Atendimento } \\
\text { profissional }\end{array}$} & \multirow{3}{*}{5} & \multirow{3}{*}{$8 \%$} & Atendimento com seriedade. & 1 & $2 \%$ \\
\hline & & & & & & Estabilidade no padrão de atendimento & 2 & $3 \%$ \\
\hline & & & & & & Funcionários capacitados e com atitude profissional. & 2 & $3 \%$ \\
\hline & & & \multirow[b]{3}{*}{ Cordialidade } & \multirow{3}{*}{5} & \multirow{3}{*}{$8 \%$} & A empresa é flexível quanto a erros do contratante. & 1 & $2 \%$ \\
\hline & & & & & & $\begin{array}{l}\text { A empresa e prestativa mesmo quando ha notificaçao } \\
\text { demandando detalhamento de informações }\end{array}$ & 1 & $2 \%$ \\
\hline & & & & & & O atendimento é cordial. & 3 & $5 \%$ \\
\hline & & & $\begin{array}{l}\text { FlexIbillaade de } \\
\text { gestão }\end{array}$ & 2 & $3 \%$ & $\begin{array}{l}\text { Ha flexibilidade quanto ao formato de relatorios } \\
\text { demandados. }\end{array}$ & 2 & $3 \%$ \\
\hline \multirow{16}{*}{ Técnica } & \multirow{16}{*}{37} & \multirow{16}{*}{$60 \%$} & Confiabilidade & 1 & $2 \%$ & A apuração de quantitativos de impressão é confiável. & 1 & $2 \%$ \\
\hline & & & \multirow[b]{5}{*}{$\begin{array}{l}\text { Informações } \\
\text { claras e precisas }\end{array}$} & \multirow{2}{*}{6} & \multirow{2}{*}{$10 \%$} & Equipamento de boa qualidade & 4 & $6 \%$ \\
\hline & & & & & & Sempre há disponibilidade de insumos. & 2 & $3 \%$ \\
\hline & & & & \multirow{3}{*}{7} & \multirow{3}{*}{$11 \%$} & As informações são claras e precisas. & 4 & $6 \%$ \\
\hline & & & & & & Informações claras e precisas. & 2 & $3 \%$ \\
\hline & & & & & & $\begin{array}{l}\text { Não ha duplicidade de documentos em melo eletronıco e em } \\
\text { meio físico. }\end{array}$ & 1 & $2 \%$ \\
\hline & & & Inovação & 2 & $3 \%$ & $\begin{array}{l}\text { A empresa oferece soluçoes inovadoras, mesmo quando } \\
\text { não demandado. }\end{array}$ & 2 & $3 \%$ \\
\hline & & & & & & A apuração de quantitativos de impressão é prática & 2 & $3 \%$ \\
\hline & & & & 5 & $8 \%$ & $\begin{array}{l}\text { A requisiçao de serviços e felta de forma a facilitar o } \\
\text { controle. }\end{array}$ & 2 & $3 \%$ \\
\hline & & & Praticidade & & & O relacionamento com a contratada é pouco burocrático. & 1 & $2 \%$ \\
\hline & & & & & & $\begin{array}{l}\text { A apuraçao de quantitativos de impressao permite ser } \\
\text { auditada posteriormente. }\end{array}$ & 2 & $3 \%$ \\
\hline & & & & 9 & $15 \%$ & A empresa zela pela segurança da informação. & 2 & $3 \%$ \\
\hline & & & & $y$ & $15 \%$ & A empresa zela pela segurança jurídica. & 2 & $3 \%$ \\
\hline & & & $\begin{array}{l}\text { Segurança } \\
\text { jurídica }\end{array}$ & & & Há um bom controle financeiro e administrativo da empresa; & 3 & $5 \%$ \\
\hline & & & Velocidade e & 7 & $110 \%$ & A comunicação com o preposto da empresa é rápida. & 1 & $2 \%$ \\
\hline & & & pontualidade & 7 & $11 \%$ & $\mathrm{O}$ atendimento é rápido & 6 & $10 \%$ \\
\hline Total Geral & 62 & $100 \%$ & & 62 & $100 \%$ & & 62 & $100 \%$ \\
\hline
\end{tabular}

Fonte: Elaborado pelo autor

Para cada um dos dois fornecedores, os incidentes positivos e negativos também foram classificados pelos próprios respondentes, quanto:

a) à frequência: raramente, algumas vezes, frequentemente ou constantemente; Esta frequência, apresentada aos respondentes em forma de escala, apresenta quatro estágios crescentes de ocorrência: (i) raramente, quando o incidente nunca ou quase nunca foi percebido; (ii) algumas vezes, quando o incidente foi percebido, mas de forma nem tão rara nem muito frequente; (iii) frequentemente, quando o incidente foi percebida com mais regularidade, mas não sempre; e (iv) constantemente, quando o incidente foi percebido de forma constante, ou seja, sempre ou quase sempre.

Revista Produção Online, Florianópolis, SC, v.15, n. 4, p. 1426-1456, out./dez. 2015. 
b) ao impacto: nenhum, baixo, moderado ou alto (STRANDVIK; HOLMLUND, 2008).

A Classificação apontou que flexibilidade financeira aparece de maneira mais forte. Ela é vista como "constantemente" e muito negativa para um dos Fornecedores (empresa P2) em todas as quatro entrevistas, mas é tida como "constantemente" e muito positiva por três $(75 \%)$ dos entrevistados, relativo ao outro fornecedor (empresa P1).

Para facilitar a análise de todos os dados levantados nesta etapa, para cada classificação foi atribuído um número de pontos. Assim, quanto à frequência, itens classificados como "raramente" receberam 1 ponto, "algumas vezes" 2 pontos, "frequentemente" 3 pontos e "constantemente" 4 pontos. De forma semelhante, quanto ao impacto, os itens classificados como "nenhum" receberam 0 ponto, "baixo" 1 ponto, "moderado "2" pontos e "alto" 3 pontos.

O peso total de cada necessidade do cliente foi obtido com a multiplicação dos pontos de frequência, pelos pontos de impacto e pela quantidade de ocorrências de incidentes críticos na fase de levantamento. Houve também a multiplicação por -1 para os incidentes críticos negativos. Os resultados dos pesos de cada necessidade do cliente são apresentados na Tabela 3 abaixo.

Tabela 3 - Peso das necessidades dos clientes (impacto, frequência e ocorrência)

\begin{tabular}{lcc}
\hline Necessidade do Cliente & Prédio 1 & Prédio 2 \\
\hline Atendimento profissional & 4 & 4 \\
Confiabilidade & 0 & -2 \\
Cordialidade & 18 & 12 \\
Disponibilidade & 4 & 4 \\
Economia de recursos & 0 & 12 \\
Flexibilidade financeira & 30 & -53 \\
Flexibilidade de gestão & 4 & 2 \\
Informações claras e precisas & 4 & -12 \\
Inovação & 6 & -4 \\
Praticidade & -8 & -20 \\
Segurança jurídica & -41 & -27 \\
Velocidade e pontualidade & 29 & 28 \\
\hline Fonte: Elaborado pelo autor. & &
\end{tabular}

Revista Produção Online, Florianópolis, SC, v.15, n. 4, p. 1426-1456, out./dez. 2015. 
Pode-se perceber um destaque para a flexibilidade financeira, fortemente positiva no Prédio 1 , e fortemente negativa no prédio 2. A segurança jurídica também prevalece, mas de forma negativa em ambos os prédios. Já a velocidade e a pontualidade são tidas como outra necessidade do cliente que sobressaem de forma positiva nas duas empresas. O total dos pesos de cada necessidade do cliente por prédio demonstra uma prevalência de itens destacados como positivos para a empresa do prédio 1, e negativos para o prédio 2.

Mais uma vez, a análise com os gestores demonstrou uma diferença de desempenho entre os fornecedores que não foi apontada na sistemática utilizada pelo Acordo de Nível de Serviço (ANS).

\section{DISCUSSÃO DOS RESULTADOS}

Uma confrontação dos resultados obtidos nas etapas 2, 3 e 4 revela a ocorrências de padrões diferenciados para cada uma delas. Nesta direção, a Tabela 4 apresenta uma comparação das necessidades dos clientes levantadas nas 3 etapas.

Tabela 4 - Comparação das necessidades dos clientes levantadas nas 3 etapas

\begin{tabular}{lrrr}
\hline Necessidades dos Clientes & Etapa 2 & Etapa 3 & Etapa 4 \\
\hline Atendimento profissional & $0 \%$ & $0 \%$ & $8 \%$ \\
Confiabilidade & $0 \%$ & $18 \%$ & $2 \%$ \\
Cordialidade & $0 \%$ & $3 \%$ & $8 \%$ \\
Disponibilidade & $80 \%$ & $11 \%$ & $10 \%$ \\
Economia de recursos & $0 \%$ & $7 \%$ & $2 \%$ \\
Flexibilidade de gestão & $0 \%$ & $0 \%$ & $3 \%$ \\
Flexibilidade financeira & $0 \%$ & $0 \%$ & $19 \%$ \\
Informações claras e & $0 \%$ & $5 \%$ & $11 \%$ \\
precisas & $0 \%$ & $0 \%$ & $3 \%$ \\
Inovação & $0 \%$ & $31 \%$ & $8 \%$ \\
Praticidade & $0 \%$ & $7 \%$ & $0 \%$ \\
Resultado estético & $0 \%$ & $0 \%$ & $15 \%$ \\
Segurança jurídica & $20 \%$ & $18 \%$ & $11 \%$ \\
Velocidade e pontualidade & $100 \%$ & $100 \%$ & $100 \%$ \\
TOTAL & &
\end{tabular}

Fonte: Elaborado pelo autor. 
Das categorias de necessidades de clientes existentes na etapa 2, somente 0 resultado estético não se repete na terceira etapa. Contudo, cinco novas categorias surgem: o atendimento profissional, a flexibilidade financeira, a flexibilidade de gestão, a inovação e a segurança jurídica, caracterizando uma preocupação dos gestores não prevista nos indicadores de ANS e não detectada pelos usuários.

A praticidade e a confiabilidade surgem como categorias de maior destaque junto aos usuários na etapa 3, mas não foram previstas nos indicadores contratuais e não se destacam dentre as necessidades dos gestores (etapa 4). A cordialidade, a economia de recursos e a clareza de informações, também não representadas em ANS, surgem com maior peso entre os gestores do que entre os usuários. 0 resultado estético é a única necessidade de cliente que só aparece nas entrevistas junto aos usuários finais (etapa 3). Por fim, as duas únicas categorias de necessidade dos clientes previstas nos contratos, a disponibilidade e a velocidade, apresentam peso maior na etapa 2 que nas outras duas. No caso da disponibilidade, a diferença é grande entre a etapa 2 e as demais, mas pequena nas etapas 3 e 4 . No caso da categoria de velocidade e pontualidade, há proximidade entre os pesos a ela conferidos nas etapas 2 e 3 , que foram significativamente maiores que na etapa 3.

Na última etapa, houve significativo aumento da participação das dimensões econômica e social, com 21\% e 19\% respectivamente. Contudo, a dimensão técnica sobressai-se novamente com $60 \%$ dos itens de satisfação a ela relacionados. Cabe destacar que as categorias de necessidade de cliente de segurança jurídica e de flexibilidade financeira são as que mais predominam na etapa 4, não tendo sequer aparecido nas etapas 3 ou na 2. O resumo destes dados é mostrado na Tabela $5 \mathrm{~A}$ seguir.

Tabela 5 - Participação das dimensões de qualidade nas três etapas

\begin{tabular}{llll}
\hline Dimensão & Etapa 2 & Etapa 3 & Etapa 4 \\
\hline Econômica & $0 \%$ & $7 \%$ & $21 \%$ \\
Social & $0 \%$ & $3 \%$ & $19 \%$ \\
Técnica & $100 \%$ & $90 \%$ & $60 \%$ \\
TOTAL & $100 \%$ & $100 \%$ & $100 \%$ \\
\hline
\end{tabular}

Fonte: Elaborado pelo autor

Uma das possíveis explicações para esta melhor distribuição de pesos entre as dimensões ocorrida na última etapa pode ser atribuída ao escopo mais amplo de Revista Produção Online, Florianópolis, SC, v.15, n. 4, p. 1426-1456, out./dez. 2015. 
trabalho dos gestores de contrato. O estudo demonstra que a Qualidade de Relacionamento B2B envolve diferentes pessoas e funções com diferentes necessidades e importâncias.

\section{CONSIDERAÇÕES FINAIS}

Apesar de os resultados dos indicadores de ANS dos últimos 24 meses de execução dos contratos não apresentarem grandes variações, a percepção dos usuários quanto aos serviços prestados não foi homogênea se contrastadas empresas P1 e P2. A diferença de resultados coloca em xeque a adequação dos indicadores de ANS desenhados para contrato.

Ao se classificar as necessidades dos clientes nas três dimensões de qualidade propostas por Holmlund (2007), a saber, técnica, social e econômica, verifica-se a presença de todas as três dimensões, muito embora tenha um significativo predomínio da dimensão técnica. Pode-se afirmar que as necessidades dos clientes são predominantemente técnicas. Uma possibilidade explicativa para isto é o fato abordado de que os usuários-finais do serviço têm um contato restrito com o fornecedor, se considerado todo o escopo do relacionamento. Deve-se ainda levar em conta o alto grau de automatização dos serviços, que limita as possibilidades de interação humana entre usuários e prestador.

Muito embora o relacionamento se dê entre instituições, ele é composto em última instância por atos de pessoas que atuam como prepostos das duas organizações. Estas pessoas interagem entre si, vivenciando experiências cuja qualidade técnica, social ou econômica é percebida a partir de padrões individuais de comparação (HOLMLUND; KOCK, 1995; HOLMLUND, 1997, 2004, 2008).

Resta claro que a perspectiva de qualidade de relacionamento no caso estudado ainda não é uma realidade. A idéia de relacionamentos recíprocos, de longo prazo e mutuamente benéficos, com padrões de compartilhamento de informação e transferência de recursos (AOKI; LENNERFORS, 2013; DYER, 1996; LIKER; CHOI, 2004) contrasta com boa parte dos depoimentos de incidentes críticos descritos. Os incidentes críticos da quarta etapa relativos à dimensão econômica mostram uma interessante diferença entre as empresas pesquisadas. Uma é reconhecida por sua flexibilidade financeira, tida como positiva, enquanto a 
percepção quanto à outra é o contrário. Esta diferença nos dá indícios de padrões heterogêneos de comportamento: de um lado uma atuação autointeressada e voltada à transação, e de outro uma preocupação maior com o relacionamento, relativizando-se a transação singular. Uma explicação para este fato é a existência de normativos legais que limitam o relacionamento do Estado com seus prestadores de serviços, principalmente quanto ao tempo de relacionamento, ao custo e à flexibilidade. Estes podem incentivar um comportamento autointeressado e voltada à transação.

O trabalho apresentou uma limitação que advém do fato de que em um relacionamento há ao menos dois atores. Assim, a qualidade percebida deste relacionamento deve considerar a opinião de ambos os lados, vendedor e comprador. Na presente pesquisa, entretanto, só foi considerada a opinião de um dos lados do relacionamento. A opinião dos prestadores de serviço, embora relevante, não foi captada por complicações jurídicas advindas de uma representação de uma das empresas junto ao Tribunal de Contas do Estado de Minas Gerais, referente à licitação que veio substituir o serviço aqui pesquisado. Esta representação ocorreu na época em que se coletavam os dados do contratante e se preparava a coleta de dados dos prestadores. Por conta deste fato, a pesquisa não prosseguiu no levantamento de dados junto aos dois fornecedores.

\section{REFERÊNCIAS}

ABRAMCZUK, A. A. Os relacionamentos na cadeia de suprimento sob o paradigma da desintegração vertical de processos: um estudo de caso. Dissertação (Mestrado)Universidade de São Paulo, 23 out. 2001.

AOKI, K.; LENNERFORS, T. T. The new, improved keiretsu. Harvard Business Review, v. 91, n. 9, p. 109-114, 2013.

BDMG, G. D. M. G. Do choque de gestão à gestão para a cidadania: 10 anos de desenvolvimento em Minas Gerais. Belo Horizonte: Gráfica Ipiranga, 2013. p. 328

BITNER, M. J.; BOOMS, B. H.; MOHR, L. A. Critical service encounters: the employee's viewpoint. The Journal of Marketing, v. 58, n. 4, p. 95-106, 1994. http://dx.doi.org/10.2307/1251919

BITNER, M. J.; BOOMS, B. H.; TETREAULT, M. S. The Service encounter: diagnosing favorable and unfavorable incidentes. Journal of Marketing, v. 54, n. 1, p. 71-84, 1990. http://dx.doi.org /10.2307/1252174 
BRESSER-PEREIRA, L. C. A reforma do Estado dos anos 90 lógica e mecanismos de controle. Lua Nova Revista de Cultura e Política, v. 45, p. 49-96, 1998.

CHOPRA, S.; MEINDL, P. Gestão da cadeia de suprimentos. São Paulo: Prentice Hall Brasil, 2011. p. 536

DYER, J. H. How Chrysler created an American keiretsu. Harvard Business Review, v. 74, p. 42-52, 1996.

EDVARDSSON, B.; ROOS, I. Critical incident techniques: Towards a framework for analysing the criticality of critical incidents. International Journal of Service Industry Management, v. 12, n. 3, p. 251-268, 2001. http://dx.doi.org/10.1108/EUM0000000005520

FLANAGAN, J. C. The critical incident technique. Psychological bulletin, v. 51, n. 4, p. 327 , 1954.

GARVIN, D. A. What does "product quality" really mean. Sloan Management Review, v. 1, 1984.

GERRING, J. What is a case study and what is it good for? American political science review, v. 98, n. 02, p. 341-354, 2004. http://dx.doi.org/10.1017/S0003055404001182

GRÖNROOS, C. Marketing: gerenciamento e serviços. Rio de Janeiro: Elsevier/Campus, 2009. p. 481

HAYES, B. E. Medindo a satisfação do cliente: desenvolvimento e uso de questionarios. Rio de Janeiro: Qualitymark, 2001. p. 209

HOLMLUND, M. Perceived quality in business relationships. Helsinki: Swedish School of Economics and Business Administration Helsinki, 1997. p. 336

HOLMLUND, M. Analyzing business relationships and distinguishing different interaction levels. Industrial Marketing Management, v. 33, n. 4, p. 279-287, 2004.

http://dx.doi.org/10.1016/S0019-8501(03)00057-9

HOLMLUND, M. Suggesting and comparing different scopes on quality management: Production, service, relationship, and network. Total Quality Management \& Business Excellence, v. 18, n. 8, p. 847-859, 2007. http://dx.doi.org/10.1080/14783360701350466

HOLMLUND, M. A definition, model, and empirical analysis of business - to -business relationship quality. International Journal of Service Industry Management, v. 19, n. 1, p. 32-62, 14 mar. 2008. http://dx.doi.org/10.1108/09564230810855707

HOLMLUND, M.; KOCK, S. Buyer perceived service quality in industrial networks. Industrial Marketing Management, 1995. http://dx.doi.org/10.1016/0019-8501(94)00038-X

LARSON, P. D. Public vs. private sector perspectives on supply chain management. Journal of Public Procurement, v. 9, n. 2, p. 222-247, 2009.

LIKER, J. K.; CHOI, T. Y. Building deep supplier relationships. Harvard Business Review, v. 82, p. 104-113, 2004. 
MARTINS, G. DE A. Estudo de caso: uma estratégia de pesquisa. São Paulo: Editora Atlas, 2006.

PIETRO, M. S. Z. DI. Direito administrativo. 27. ed. São Paulo: Editora Atlas, 2015.

PIRES, S. R. I.; VIVALDINI, M. Operadores logísticos: integrando operações em cadeias de suprimento. São Paulo: Editora Atlas, 2010. p. 232

PORTER, M. Estrategia competitiva. Rio de Janeiro: Edtora Campus, 2004. p. 409

STRANDVIK, T.; HOLMLUND, M. How to diagnose business-to-business relationships by mapping negative incidents. Journal of Marketing Management, v. 24, n. 3-4, p. 361-381, 2008. http://dx.doi.org/10.1362/026725708X306149

TADELIS, S. Public procurement design: Lessons from de private sector. International Journal of Industrial Organization. Volume 30, Issue 3, Maio 2012, Pg 297-302, http://dx.doi.org/10.1016/j.ijindorg.2012.02.002

TORRES JÚNIOR, N. Operações em Serviços de Resultados Ulteriores: diretrizes gerenciais para um melhor desempenho. Tese (Doutorado)- Departamento de Engenharia de Produção da Escola Politécnica da Universidade de São Paulo. São Paulo, 2007.

YIN, R. K. Estudo de caso: planejamento e métodos. Porto Alegre: Editora Bookman, 2001. v. 2 p. 248

ZHENG, J. et al. An analysis of research into the future of purchasing and supply management. Journal of Purchasing and Supply Management, v. 13, n. 1, p. 69-83, 2007. http://dx.doi.org/10.1016/i.pursup.2007.03.004

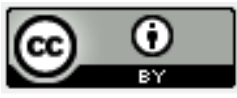

Artigo recebido em 28/01/2015 e aceito para publicação em 16/09/2015

DOI: http://dx.doi.org/ 10.14488/1676-1901.v15i4.1975 